\title{
A saúde permeada pela espiritualidade
}

\section{Health permeated by spirituality}

La salud permeada por la espiritualidad

Pedro Pereira Borges ${ }^{1}$

Rafael de Sousa Ferreira ${ }^{2}$

Isabela Diamante ${ }^{3}$

${ }^{1}$ Doutor em Ciências Sociais pela PUC-SP e Professor no Programa de Mestrado em Desenvolvimento Local da Universidade Católica Dom Bosco. E-mail: pobojari@ucdb.br

${ }^{2}$ Bacharel em Direito pela Universidade Católica Dom Bosco (UCDB) E-mail: rafaelsousa014@hotmail.com

${ }^{3}$ Bacharel em Direito pela Universidade Católica Dom Bosco (UCDB) E-mail: isabeladiamante@hotmail.com 
Resumo: A espiritualidade sempre fez parte da esfera do homem, mas, quando se trata de uma vida saudável, não é raro encontrar teorias e abordagens que procuram excluir a espiritualidade da vida humana. O Artigo apresentado trata de um estudo sobre a espiritualidade como uma condição básica para uma boa saúde, seja física ou psíquica. Outrossim, procurou mostrar que alguns argumentos que acusam a falta de cientificidade da espiritualidade não se sustentam, especialmente nas questões psíquicas, em que cada vez mais cresce a importância de uma vida espiritual saudável. Nesse sentido, foi dedicado uma parte especial para explanar sobre a logoterapia e algumas de suas abordagens empíricas, que comprovam a eficácia de uma vida espiritual saudável.

Palavras-chave: saúde, espiritualidade, logoterapia.

Abstract: The spirituality has always been a part of human's nature, but when it is about a healthy life its not rare to find theories that try to exclude the spirituality from human's life. The presented article is about a study of spirituality as a basic condition for a good health, physical and psychic. This article also tried to demonstrate some arguments that shows the lack of science of spirituality does not subsist, specially in psychic questions, in which the importance of a healthy spiritual life grows more and more. A special part was dedicated to treat about logotherapy and some empiric approaches, that proves the efficiency of a healthy spiritual life.

Key words: health, spirituality, logotherapy.

Resumen: La espiritualidad siempre ha sido parte de la esfera del hombre, pero cuando se trata de la vida sana, no es raro encontrar teorías y enfoques que buscan excluir la espiritualidad de la vida humana. El artículo que se presenta es un estudio de la espiritualidad como una condición básica para una buena salud, ya sea física o psicológica. Por otra parte, trató de demostrar que algunos de los argumentos que acusan la falta de espiritualidad científica no se sostienen, especialmente en asuntos psíquicos, en los que crecen cada vez más importancia de una vida espiritual saludable. En este sentido, una parte especial del artículo se dedica a explicar acerca de la terapia de la logoterapia y algunos de sus aproximaciones empíricas que demuestran la eficacia de una vida espiritual saludable.

Palabras clave: salud; espiritualidade; logoterapia. 


\section{INTRODUÇÃO}

A Espiritualidade sempre foi um mecanismo, por assim dizer, de cura e promoção da saúde, não só quando a ciência era escassa, já que os tratamentos místicos eram as únicas opções. Com o avanço da ciência, fez-se necessário abandonar alguns dos "conhecimentos" místicos, visto que realmente não só não possuíam cientificidade, como também não produziam saúde. No entanto, mesmo com o avanço científico, a espiritualidade nunca deixou o homem, ou melhor, o homem nunca abandonou a espiritualidade. Dessa forma, tornam-se frustradas certas ideias, em especial as disseminadas por alguns mestres da suspeita, como Nietzsche, Marx e especialmente Freud, que viam a religião e/ou a espiritualidade como um problema, ou uma neurose, como a própria psicanálise afirma.

Atualmente, cada vez mais se admite a eficiência da espiritualidade na vida humana, em especial na saúde, e os avanços científicos, que muitos acreditam promover o enfraquecimento da fé, têm-se mostrado justamente contrário: a fé parece ter mais cientificidade do que se imagina.

Nesse tocante, o presente trabalho procurou mostrar que alguns argumentos que acusam a falta de cientificidade da espiritualidade não se sustentam, especialmente nas questões psíquicas, em que cada vez mais cresce a importância de uma vida espiritual saudável.

$\mathrm{O}$ artigo que se apresenta ao leitor versa sobre a espiritualidade e a saúde. O artigo foi dividido em cinco tópicos. No primeiro, será vislumbrada a relação entre a neurociência e as questões transcendentes, de maneira que será possível observar como está atualmente a relação entre duas esferas que parecem figurar em polos diferentes. No segundo tópico, será abordada a espiritualidade e a sua relação com a promoção da saúde, ou seja, não a limitando apenas a um êxtase de curas milagrosas, mas de um sentido mais profundo em relação 
à vida humana. No próximo tópico, será feita uma exposição acerca do problema do sentido da doença, um tópico que aborda questões mais filosóficas e antropológicas sobre a doença em relação ao homem. No quarto tópico, dando continuidade à questão do sentido na doença, apresentam-se também questões científicas em relação a esse problema, abordando a Logoterapia, de Viktor Frankl, que, de maneira empírica, vivenciou o sentido do sofrimento. Por fim, no quinto tópico, buscar-se-á mostrar a importância da espiritualidade como promoção de saúde.

\section{NEUROCIÊNCIA E A EXPERIÊNCIA DO TRANSCENDENTE}

Via de regra, a ciência quase sempre tratou a questão religiosa e espiritual como um tabu. Na psicanálise, em especial para o seu criador, Sigmund Freud, a religião e a crença não possuíam qualquer embasamento científico e, por conseguinte, se processaria no "vácuo", quase como uma falha cerebral. Contudo a ciência tem revelado que a fé está tão ligada à fisiologia humana que já não se pode comungar da ciência sem entrar no campo da fé e vice-versa.

Com a descoberta de que o cérebro é o órgão principal que regula as emoções, e não o coração, como se pensava antigamente, a relação entre fisiologia e espiritualidade ganhou novo enfoque. A neurociência tem sido uma ponte entre a fé e a razão, pois, por seu intermédio, está sendo possível, mesmo que parcialmente, serem verificados cientificamente aspectos significativos da fé.

Não se trata de trazer a fé para o campo da tangibilidade, visto que o seu próprio conceito traz em si a marca da relação com o invisível (cf. Hb 11,1), mas, com o avanço da neurociência, resta clara a inconsistência de certos argumentos psicanalíticos a respeito da fé, pois "possuímos razoável evidência científica de que existem áreas no cérebro humano responsáveis pela geração de uma consciência 
espiritual ou religiosa, ali instalada pela própria natureza ou por seu Criador" (MARINO, 2005, p. 54).

Nesse sentido, têm-se desenvolvido diversos estudos para desmistificar cada vez mais a crença de que a espiritualidade seja algo externo ao homem. Segundo Marino, é possível observar como as áreas do cérebro trabalham quando estão em oração e meditação, ocorrendo uma ativação do giro cíngulo ${ }^{1}$ e do córtex pré-frontal ${ }^{2}$, de maneira que:

Durante os estados meditativos, se a ativação do córtex pré-frontal à direita produzir aumento de atividade na região talâmica, ocorrerá uma diminuição de informações sensoriais ao lóbulo parietal póstero-superior e de impulsos às áreas da visão. Estudos com Spect realizados durante estados meditativos demonstraram um aumento da atividade talâmica proporcional aos níveis de atividade no córtex pré-frontal. (MARINO, 2005, p. 47).

Marino (2005) traz à luz o famoso experimento do pesquisador Michael A. Persinger, experimento feito com pacientes voluntários, que usaram um capacete especial que produzia nos hemisférios cerebrais fracos e complexos campos magnéticos gerados por computador. A maioria dos participantes, inclusive ateus, relatou sentir uma presença para além de seus sentidos, em suma, observaram um "ser sensível". O estudo ficou conhecido como "experiência da divindade", no qual o hemisfério cerebral direito igualava-se ao esquerdo. A respeito do hemisfério direito, o autor recorda a poética frase do neurocientista Arthur Mandel (apud MARINO, 2005, p. 24): "O reino dos céus pode ser encontrado no lobo temporal direito".

\footnotetext{
${ }^{1}$ Uma das três subdivisões do sistema límbico; associado à empatia, comportamento social criativo e cuidado com a prole.

${ }^{2}$ O córtex pré-frontal consiste em uma parte do nosso cérebro, localizada no lobo frontal, responsável pela atenção, ou seja, pelo chamado na neurociência fenômeno atencional (PANTANO; ZORZI, 2009).
} 
Cada vez mais se comprovam os efeitos da oração e da meditação na saúde em geral. O cérebro humano, que para muitos era o meio para superar as crenças, tem se tornado um grande objeto de estudo, não somente científico, mas também sob a ótica da fé.

\section{ESPIRITUALIDADE COMO UM PRESSUPOSTO DE SAÚDE}

Segundo a Organização Mundial da Saúde (OMS, 1946), a saúde é "um estado de completo bem-estar físico, mental e social e não somente ausência de afecções e enfermidades". Evidentemente, a terminologia "espiritualidade" não aparece de forma extrínseca. Contudo, quando se toca na questão mental e social, ou na própria Psyche, necessariamente, a sua definição abrange a espiritualidade e outros conceitos.

Dessa forma, a doença está muito além de um mero fator físico, que, em última instância, pode ser resolvido por um modelo biomédico, pois, "atualmente, muitas pessoas têm a percepção de que a saúde é mais do que o conserto de um corpo doente [...], requer a relação adequada consigo mesmo, com o ser humano, com o universo e, por fim, com Deus" (GRUN, 2008, p. 13).

Na carta encíclica Caritas in Veritate, o Papa Bento XVI (2009) denunciou uma sociedade vítima do psicologismo e do tecnicismo científico, que culmina em uma visão reducionista do homem:

Um dos aspectos do espírito tecnicista moderno é palpável na propensão a considerar os problemas e as moções ligados à vida interior somente do ponto de vista psicológico, chegando-se mesmo ao reducionismo neurológico. Assim esvazia-se a interioridade do homem e, progressivamente, vai-se perdendo a noção da consistência ontológica da alma humana, com as profundidades que os Santos souberam pôr a descoberto. O problema do desenvolvimento está estritamente ligado também com a nossa concepção da alma do homem, uma vez que o nosso eu acaba muitas vezes reduzido ao psíquico, e a saúde 
da alma é confundida com o bem-estar emotivo. (BENTO XVI, 2009, p. 135).

É inevitável o contexto espiritual, pois a espiritualidade, diferentemente da religião, não é uma escolha. Todo ser humano, inclusive os ateus, são permeados pela espiritualidade. Trata-se de uma característica imanente do ser humano. O que se pode escolher é vivenciá-la ou não.

Em contrapartida, todo aquele que crê também experimenta a descrença, tendo em vista que "a promessa bíblica de que a verdade libertará não implica que uma pessoa verdadeiramente religiosa se encontra em uma posição de invulnerabilidade quanto às neuroses" (FRANKL, 2011, p. 166). Ou seja, todo ser humano é permeado por opostos dentro de si, amor e ódio, crença e descrença etc.

\section{O PROBLEMA DO SENTIDO NA DOENÇA}

Uma condição indispensável para a saúde é encontrar um sentido para a própria vida, no entanto, constantemente - ao longo da História - pareceu inconcebível procurar ou afirmar que as doenças e o sofrimento possam ser dotados de um sentido. Porquanto, habitualmente, isso soa como uma esperança de cunho religioso.

Na psicanálise, tal atitude é vista como um mecanismo de defesa. No entanto, "a busca do indivíduo por um sentido é a motivação primária em sua vida, e não uma 'racionalização secundária' de impulsos instintivos" (FRANKL, 2008, p. 124).

Para Sheen (2015, p. 13):

Em toda a gama da psicologia moderna nada há escrito a respeito das frustações, temores e ansiedades que possa ser mesmo fracamente comparado, em profundeza ou vastidão, com o tratado de São Tomás sobre as paixões, com as confissões de Santo Agostinho ou com o tratado de Bossuet sobre a concupiscência. 
Nesse sentido, sempre de novo se indaga sobre o "porquê" de tal doença, não se limitando apenas à questão física, mas o que espiritualmente ela tem a dizer. A doença é, desse modo, perpassada por todas as áreas do portador, desembocando não somente numa cura direta, mas no remodelamento físico, mental e espiritual, isto é, "a psicossomática muitas vezes enfatiza que os distúrbios do corpo não são coincidência e meramente exteriores, mas refletem a verdadeira condição da pessoa, seus desejos e necessidades inconscientes e suas repressões e suplantações" (GRUN, 2008, p. 19).

Por intermédio da Logoterapia, Viktor Frankl mostrou que a falta ou um problema de sentido pode acarretar em uma frustração existencial e, consequentemente, naquilo que chamou de Neuroses Noogênicas. Estas que "não surgem de conflitos entre impulsos e instintos, mas de problemas existenciais" (FRANKL, 2008, p. 126).

A questão do sentido no sofrimento não é vista somente como um tabu, mas como uma visão incompreensível da realidade, propagada pela moral judaico-cristã. Para Ratzinger (2005, p. 32):

Hoje, o que se pretende é eliminar o sofrimento da face da terra. Para o indivíduo, isso significa evitar a todo o custo a dor. No entanto, precisamos enxergar também que é precisamente dessa forma que o mundo se torna muito duro e muito frio. A dor é parte do ser humano. Quem quisesse realmente livrar-se do sofrimento, antes de mais nada teria que livrar-se do amor; não há amor sem sofrimento, pois o amor sempre exige certa dose de sacrifício: diante das diferenças de temperamento e dos dramas humanos, sempre trará consigo renúncia e dor.

Igualmente, Viktor Frankl refutou, por assim dizer, na prática (em sua experiência nos Campo de Concentração) algumas proposições da psicanálise freudiana, explanando o "poder curador" que o sentido da vida é capaz de realizar na existência pessoal e no mundo:

Sigmund Freud afirmou em certa ocasião: "Imaginemos que alguém coloca determinado grupo de pessoas, bastante diversificado, numa mesma e uniforme situação de fome. Com 
o argumento da necessidade imperativa da fome, todas as diferenças da necessidade imperativa da fome, todas as diferenças individuais ficarão apagadas, e em seu lugar aparecerá a expressão uniforme da mesma necessidade não satisfeita". Graças a Deus, Sigmund Freud não precisou conhecer os campos de concentração do lado de dentro. Seus objetos de estudo deitavam sobre divãs de pelúcia desenhados no estilo da cultura vitoriana, e não na imundice de Auschwitz. Lá, as "diferenças individuais" não se "apagaram", mas, ao contrário, as pessoas ficaram mais diferenciadas; os indivíduos retiraram suas máscaras, tanto os porcos como os santos. (FRANKL, 2008, p. 174-175).

A questão do sentido está longe de ser apenas algo "espiritual". Sem dúvida, sua essência é transcendental, mas também é perfeitamente permeada pela vida cotidiana, com suas alegrias e dores, enfim, com todos os seus opostos.

\section{SAÚDE: AUSÊNCIA DE DOENÇA, OU AUSÊNCIA DE SENTIDO?}

Talvez a saúde como ausência de doença seja um assunto superado, no entanto não causa nenhuma surpresa dizer que a saúde é o oposto de dor, culpa e morte, o qual Frankl chamou de "tríade trágica”. Afinal, é possível falar de uma vida saudável quando se está dentro desta tríade? Outra pergunta que deve ser feita é se uma vida sem essa tríade é o próprio conceito de uma vida saudável e feliz? Parece que não...

Uma vida saudável não está intercalada com o modelo "saudável" que se vê na contemporaneidade, quase que discriminadora a quem sofre. "Em dias mais felizes, os filósofos discutiam o problema do homem: agora discutem o homem como um problema" (SHEEN, 2015 , p. 8). Por seu turno, Frankl exalta o sentido da vida independente de qual seja a situação na qual a pessoa se encontra, o que acabou por culminar na teoria do "otimismo trágico", ou seja, que podemos 
encontrar sentido naquela tríade trágica, isolada pela sociedade sob o rótulo de "doença".

Frankl relata um caso curioso de um ouvinte de suas palestras que Ihe escreveu uma carta contando a sua história de superação: após um acidente ele ficara tetraplégico e, depois de ser permeado por esta "tragédia" - na qual se via como desprovido de utilidade para o mundo (o inverso de uma vida "saudável") -, acabou, aos poucos, descobrindo o sentido de sua vida - que desconhecia quando tinha todos os movimentos e nenhuma doença. Agora, não só se sentia bem, como também resolvera cursar psicologia. Frankl ficou tão entusiasmado com o jovem, que o chamou para uma de suas conferências para ministrar uma palestra.

Com efeito, o jovem realizou as três etapas do Otimismo Trágico, isto é, "transformar o sofrimento numa conquista e numa realização; extrair da culpa oportunidade de mudar a si mesmo para melhor e fazer da transitoriedade da vida um incentivo para realizar ações responsáveis" (FRANKL, 2008, p. 161).

Uma vida rica em espiritualidade ou até mesmo religiosidade não significa uma vida sem doenças físicas e mentais, e, quando as têm, em nada afeta a dimensão espiritual. Frankl (2011 p. 165) relata a carta de uma irmã carmelita:

A depressão é minha companhia em tempo integral. Ela torna minha alma pesada. Onde foram parar meus ideais? Onde estão a grandeza, a beleza e a bondade, com as quais, um dia, me comprometi? Não há nada, além de tédio, no interior do qual me vejo aprisionada. Tenho vivido como se tivesse sido jogada no vácuo, pois, às vezes, até a experiência de dor me é inacessível. E, se eu não portasse a crença de que não sou senhora de minha vida, eu mesma já a ateria levado. Deus constrói uma catedral em cada alma Na minha, sua escavação está perto de atingir a base. O que tenho a fazer é apenas manter-me firme no meu lugar, quando quer que eu seja atingida por sua pá. 
A doença, quando perpassada por um sentido, não somente torna-se suportável - como se fosse um mero mecanismo de defesa (frívolo) - mas também desemboca até mesmo em potencialidades humanas antes inimagináveis.

\section{A ESPIRITUALIDADE COMO PROMOÇÃO DE SAÚDE}

Com o "rompimento" do modelo biomédico, a nova lei é a promoção da saúde, como busca de uma visão holística do homem. Mas, como se pode verificar, o corpo mortal ainda é visto como sagrado e a única fonte de doença e de cura. Em contrapartida, nunca se falou tanto em doenças mentais e até espirituais como atualmente. Desse modo, como é possível uma prevenção e até mesmo um tratamento dessa magnitude? Com o advento das novas descobertas da Neurociência e de outras áreas das ciências, não se pode mais negar a existência do "divino" e do "transcendental" na mente humana, e, principalmente, a sua atuação na existência do ser humano.

A principal indagação a ser estudada é: como a espiritualidade pode atuar na promoção da saúde? Embora a espiritualidade seja uma experiência singular do indivíduo, em regra, ela sempre esteve e está a ligada a uma ação bilateral, entre o criador e a criatura e entre o líder espiritual e o fiel, ou seja, aceitar a espiritualidade não significa mergulhar-se em qualquer experiência mística e, consequentemente, destilar modelos de saúde. Para Jung (1987, p. 49):

Se o paciente é católico praticante, eu o aconselho a confessar-se e a comungar, para resguardar-se de uma experiência imediata, que poderia ser superior a suas forças. Com os protestantes, a tarefa em geral não é assim tão fácil; o dogma e os ritos enfraqueceram a tal ponto, que perderam grande parte de sua eficácia. Via de regra, não há confissão e os pastores compartilham da antipatia geral frente aos problemas psicológicos e infelizmente da ignorância generalizada em matéria 
de psicologia. Os sacerdotes católicos e diretores de almas, em geral, possuem maior habilidade psicológica e às vezes uma compreensão mais profunda. Além disso, os pastores protestantes passaram por um treinamento cientifico em alguma Faculdade de teologia que, com seu espirito critico, mina a ingenuidade da fé, ao passo que na educação de um sacerdote católico a poderosa tradição histórica geralmente fortalece a autoridade da instituição.

Vista assim, a espiritualidade também possui os seus espinhos, de maneira que não é somente uma crença transcendental, mas, sobretudo, também implica condições e responsabilidades, pois se a saúde não é só o estado físico, também está longe de ser apenas uma crença metafísica.

Segundo Gomes (1988), encontrar um sentido na vida também pode ser considerado como uma promoção de saúde via espiritualidade, sendo que o sentido é uma realidade que está voltada para o futuro:

Nem todos conflitos são necessariamente neuróticos; o sofrimento não é um fenômeno patológico e chega em muitas ocasiões a ser necessário para o crescimento da pessoa." Por esta razão, a tentativa de encontrar um sentido para a vida, apesar de incendiar a nossa alma com as chamas da angústia, não pode ser compreendida como transtorno mental, como entendia Freud. (GOMES, 1988, p. 47).

Se existe uma área da saúde na qual se tenta banir a espiritualidade, esta área, com certeza, é a da saúde mental. A começar pela psicanálise de Sigmund Freud, o qual denominou a religião como uma neurose e justificou todos os comportamentos transcendentes como mecanismos de defesas e afins.

Por sua vez, a psicologia até Frankl simplesmente ignorou a espiritualidade apenas como um viés da saúde. Ele a elevou a mais do que um sistema cultural no qual o homem está inserido. Atualmente, há 
ainda teorias sociais que admitem a espiritualidade e a religião apenas como um aspecto cultural que parecem simplesmente fechar os olhos para essa realidade. "A psicologia profunda segue o ser humano até as profundezas de seu instinto, mas muito pouco às profundezas de seu espírito" (FRANKL, 2007, p. 5). Por seu turno, Chesterton (1923, $\mathrm{s} / \mathrm{p}$ ) faz uma dura crítica a todas as teorias que procuram limitar o ser humano como mero instinto:

Uma moda consiste em conceber tudo acerca do nascimento como estando relacionado ao sexo. [...] É típico destas manias que elas não conseguem convencer a mente, mas elas turvam-na. Nenhuma leva em conta as verdadeiras e sérias conclusões deste mundo. Mas cada uma pode provocar feridas profundas e desastrosas na mente do homem comum... em vez de encontrarmos perdão para os nossos pecados, pecados que cometemos por nossa própria culpa, obtemos a mais fantástica lengalenga mental, envolvida no manto da ciência, que nos explica que os nossos pecados não são pecados, e o que quer que seja que tenhamos feito, não foi nossa culpa. O mal perpetuado por esta falácia tem duas consequências: nós tornamo-nos menos responsáveis pelas nossas ações pecaminosas e aguardamos um perdão que nunca chega. É o casamento de Freud com Darwin. Uma pseudociência com outra.

Não se trata de trabalhar a religiosidade como o aspecto principal para a psicoterapia (embora, em alguns casos, isso seja perfeitamente possível). Com o advento da Logoterapia, as questões espirituais e religiosas não ganharam um foco especial, apenas passaram a ser vistas com a importância que the é devida, simplesmente por ser um fator importante no homem, ele crendo ou não.

Cada vez mais a saúde terá que se confrontar com a espiritualidade, como um pilar indispensável para a saúde, sendo necessários estudos que possam desenvolver mecanismos de interação entre os profissionais da saúde e a espiritualidade. 


\section{CONSIDERAÇÕES FINAIS}

É impossível reduzir a saúde a um mero conceito, ou a uma forma reducionista, como muitos tentaram em suas abordagens. $\mathrm{Na}$ realidade, cada vez mais esse leque se abre, possibilitando novas interpretações, visto que o homem está em constante mudança.

É possível concluir que o homem deseja o infinito, e que este só é possível por intermédio da espiritualidade, sem a qual, o homem adoece. Outrossim, o bem-estar físico, por si só, não é capaz de eliminar o sofrimento psíquico, e mesmo os dois estando "saudáveis" não satisfazem uma alma doente, que busca um sentido na vida.

Com efeito, mesmo com os avanços nas áreas da saúde, ainda é possível observar uma descrença ou até mesmo negligência em face à espiritualidade, fundamentada muitas vezes em filosofias niilistas, filosofias que não são capazes de fornecer uma resposta ao mal do século: o vazio existencial, que só pode ser permeado pela espiritualidade.

\section{REFERÊNCIAS}

BENTO XVI. Caritas in veritate. São Paulo: Paulinas, 2009.

CHESTERTON, Gilbert K. The game of psychoanalysis. 1923. Sociedade Chesterton Portugal. Disponível em: <http://sociedadechestertonportugal. blogspot.com.br/2013/07/o-jogo-da-psicanalise.html>.

FRANKL, Viktor. A vontade de sentido. São Paulo: Paulus, 2011.

. Em busca de sentido. Petrópolis, RJ: Vozes, 2008.

. A presença ignorada de Deus. Petrópolis, RJ: Vozes, 2007.

GOMES, José Carlos Vitor. A prática da psicoterapia existencial: logoterapia - uma aproximação à obra de Viktor Frankl e o movimento humanístico existencial da Escola de Viena. Petrópolis, RJ: Vozes, 1988.

GRUN, Anselm. A saúde como tarefa espiritual. Petrópolis, RJ: Vozes, 2008. 
JUNG, C. J. A Psicologia e religião. Petrópolis, RJ: Vozes, 1987.

MARINO, Raul Jr. A religião do cérebro - as novas descobertas da neurociência a respeito da fé humana. São Paulo: Gente, 2005.

ORGANIZAÇÃO MUNDIAL DA SAÚDE (OMS). Constituição da Organização Mundial da Saúde (OMS/WHO) - 1946. Biblioteca virtual de direitos humanos. Disponível em: <http://www.direitoshumanos.usp.br/index.php/ OMS-Organiza\%C3\%A7\%C3\%A3o-Mundial-da-Sa\%C3\%BAde/constituicaoda-organizacao-mundial-da-saude-omswho.html>. Acesso em: ago. 2016. PANTANO, Telma; ZORZI, Jaime Luiz (Org.). Neurociência aplicada à aprendizagem. São José dos Campos, SP: Pulso Editorial, 2009.

RATZINGER, Joseph. Selecção de textos, 2005. Disponível em: <http://img. cancaonova.com/noticias/pdf/276398_CitacoesCardealRatzinger.pdf>.

SHEEN, Fulton. A paz da alma. São Paulo: Molokai, 2015. 
